\title{
Challenges in Creating Evidence in Environmental Health Risk Assessments: The Example of Second-Hand Smoke
}

\author{
Florian Fischer \\ Department of Public Health Medicine, School of Public Health, Bielefeld University, P.O. Box 100131, \\ Bielefeld 33501, Germany; f.fischer@uni-bielefeld.de; Tel.: +49-0521-106-4257 \\ Academic Editor: Palmiro Poltronieri \\ Received: 9 September 2015; Accepted: 19 January 2016; Published: 30 January 2016
}

\begin{abstract}
Public health interventions are directed to influence the (state of a) risk factor, either by behavioral or environmental changes. Therefore, environmental health risk assessments are highly relevant for public health decision making and policy development. The credibility of an environmental health risk assessment depends, to a large extent, on the strength of the scientific evidence on which it is based. In this article, the main challenges for assessing the impact of a potential adverse health effect from an environmental pollutant are described. Second-hand smoke (SHS) was chosen to illustrate the current state of evidence. The assessment of the impact of potential adverse health effects from environmental risk factors is dependent on several issues, such as the hypothesized health outcome, the nature of the exposure, the dose-response-relationship and the variability and susceptibility of the exposed population. The example of SHS exposure highlights the need for evidence-based public health. Several challenges in terms of study design, assessment methods, as well as data analysis and synthesis with respect to the stratification of results, and consideration of bias and confounding exist. Future research needs to take into account which methods and techniques will be used to generate evidence for population-level decisions.
\end{abstract}

Keywords: second-hand smoke; evidence; exposure; health effects; environmental risk

\section{Introduction}

Improving the evidence in public health allows for better decisions of healthcare professionals and health authorities [1]. The concept of evidence-based medicine is understood as "the conscientious, explicit and judicious use of current best evidence in making decisions about the care of individual patients" [2]. According to this concept, decision making should be based on a clearly defined set of methods. Systematic reviews are used for the collection and grading of evidence. Evidence-based medicine focuses on clinical interventions which are mainly single-component. Typically, they are designed to influence one clearly defined health outcome. Therefore, causal pathways are relatively short and direct from a clinical intervention to an outcome $[1,3,4]$.

In contrast to evidence-based medicine in the clinical setting, evidence-based public health has to deal with multiple health and socials goals [5]. Public health focuses on the promotion of health or prevention of diseases in populations or targeted sub-populations [6]. To reach this target, a wide range of activities, such as policies, laws, organizational or community development, education, technical development, service development and delivery, and communication, are performed [1,7]. The pathways between causes-such as risk factors or interventions-and outcome(s) are mainly long and complex [1,4]. Therefore, the consideration of more distal effects is as important as assessing the direct impact [7]. The goal of public health is among others to influence the (state of a) risk factor, either by behavioral or environmental changes. Therefore, two different approaches for evaluating 
public health interventions are possible: (1) the effect of the intervention in risk factor reduction and (2) the effect of risk factor reduction on an health outcome [1].

This highlights the major importance of valid assessments of risk factors in determining the effect on population's health. During the last decade, the assessment of environmental risk factors and the adverse health effects associated with these risk factors received more public and scientific interest [8]. In epidemiology, the concept of attributable risks is used to illustrate the difference in the rate of a condition between an exposed and unexposed population. Environmental health risk assessment is highly relevant for public health decision making and policy development. The validity of the environmental health risk assessment depends, to a large extent, on the strength of the scientific evidence on which it is based [9]. Therefore, concepts and methods of evidence-based public health are particularly relevant in the context of environmental risk factors and the assessment of associated adverse health effects. In this article, the main challenges for assessing the impact of a potential adverse health effect from an environmental pollutant are described. Second-hand smoke (SHS) was chosen as an example to illustrate the current state of evidence regarding the below mentioned factors. Based on methodological aspects of studies dealing with SHS exposure, challenges for studies dealing with health effects of environmental risk factors are described.

\section{Challenges in Creating Evidence in Environmental Health Risk Assessments}

The whole process of assessing needs in relation to environmental health risks and evaluating actions in public health is comparable to the principles of clinical work for the treatment of an individual patient. The main factors of this process are depicted in the inner cycle of Figure 1. According to this, patients become ill due to a cause of disease. Therefore, a physician assesses the health status of a patient by a range of diagnostic techniques. In the following assessment of the patient's situation the diagnosis is important, but also other aspects such as patients' preferences are taken into account. As a last step, a treatment will be chosen and performed. According to the paradigm of evidence-based medicine, all these steps will be based on scientific evidence [10].

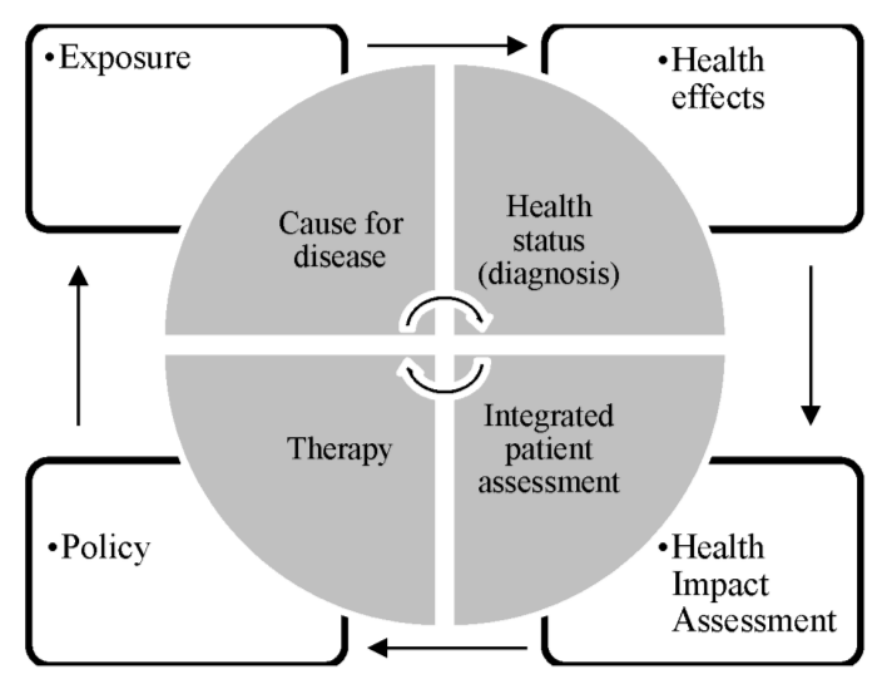

Figure 1. Decision processes in evidence-based medicine and public health (own illustration based on [10]).

The public health decision process in terms of evidence-based public health is shown in the outer cycle of Figure 1. The main challenges in creating evidence, described in the following part in more detail, exist in the clear definition and adequate assessment of exposure as well as effect, the attribution of exposure to health effects, and the development of adequate policies. 


\subsection{Selection of Study Design}

In epidemiology, several study designs are possible, and no gold-standard such as randomized controlled trials in evidence-based medicine exist. The chosen study design in public health is mainly dependent on the prevalence of risk factor and disease. For assessing the impact of SHS on health outcomes, mainly cohort studies and case-control are used und should be incorporated in evidence syntheses. Firstly, because of their higher level of evidence compared to cross-sectional studies and, secondly, because most cross-sectional studies provide inconsistent findings on the relationship between SHS exposure and adverse health effects [11]. Therefore, the study design is of major importance, particularly in the research field of effects attributable to a risk factor such as SHS exposure. Furthermore, until now existing studies have used a relatively short duration of follow-up. Therefore, the statistical power of many studies examining the risks of SHS exposure associated with chronic diseases is limited. This may lead to an underestimation of the true association between SHS exposure and diseases with a long latency [12-14]. In addition, studies on the effects of SHS need to take into account the dose-response relationship between SHS exposure and adverse health outcomes. It is suggested that the short-term effects attributable to SHS exposure are similar to the effects of main-stream smoking, which have been known to disappear after several years of non-exposure [15]. This highlights the relevance of observing short- as well as long-term effects, the type of effect and dose-response relationship. Furthermore, the assessment of cumulative or period-specific exposures and vulnerable periods is needed.

Studies dealing with the effects of SHS exposure frequently included only a few cases. In addition, the comparability of results is limited, because different kinds of comparisons between study participants were performed: Direct analyses compare the risk for non-smokers exposed to SHS with the risk for unexposed non-smokers. In indirect analyses, the risk for exposed non-smokers is estimated from the risk for active smokers [16]. These differences in methods have to be considered during interpretation. Furthermore, due to the use of different reference categories, the risk estimates from studies of active and passive smoking are not directly comparable [17].

\subsection{Key Sources of Exposure}

The inclusion of all key sources of exposure via all possible routes and all media is needed. There is a tendency for many studies to investigate adverse health effects related to a restricted, though often substantial, potential source of exposure and to ignore other sources [8]. Since many studies were unable to estimate SHS exposure outside the home, the groups of people described as "unexposed" may include a not negligible proportion of persons with SHS exposure in other settings, such as the workplace [12]. A review of nine epidemiological studies published before 1992 highlighted that the lack of data on SHS exposure outside the home was one of the major weaknesses in the epidemiological evidence [18]. Earlier on, it was considered that studies underestimated the risk caused by SHS exposure, because exposures at home may be smaller than exposures at the workplace [19]. Although this argument may have changed due to the implementation of smoke-free laws, which lead to the greatest source of SHS exposure being at home [20], it still highlights the importance of including different settings of SHS exposure. Difficulties in ascertaining SHS exposure may explain the lack of precision in several estimates [21]. Furthermore, studies that report exposure only at home or at work could lead to an underestimation of the effect because of the different employment patterns of men and women [21].

Overall, studies use various definitions of SHS exposure, focusing either on certain settings, such as home or workplace, or rely frequently just on information, such as "spousal smoking", without any further assessment of the frequency, duration or intensity of exposure [22,23]. For this reason, information on SHS exposure may be inexact or poorly reported [24-26]. Using spousal smoking, for example, as the sole marker of SHS exposure, may lead to a downward bias resulting from exposure misclassification $[27,28]$. Nevertheless, the results of epidemiologic studies on the association between 
SHS exposure and ischaemic heart diseases using spousal smoking to assess the exposure are consistent, despite differences in study designs, study populations and study locations [20,29].

\subsection{Exposure Assessment Method}

Besides adequate measurements of the outcome, in environmental epidemiology particularly the exposure assessment should be considered. Therefore, the following remarks aim to provide a short overview of methods for exposure assessment using the example of SHS. The methods for assessing the exposure to risk factors can be divided in direct measurements, such as personal monitoring or biomarkers, or indirect methods, such as exposure modeling [8]. Up to now, there is no gold standard to measure SHS exposure [30]. Using valid and reliable methods for assessing the SHS exposure should avoid misclassification bias. Until now, studies measuring the dose of SHS exposure either rely on biomarkers such as cotinine concentration or self-reported items such as the number of smokers (e.g., in a household), or exposure in terms of cigarettes per day, hours per week or pack years [31].

Although some earlier studies found that the reliability of self-classification of SHS exposure is moderate to very good $[28,32-36]$, nowadays the evidence indicates that self-reported information is an imprecise measure to assess SHS exposure $[37,38]$. The sensitivity of SHS exposure assessment by self-reports may vary between the domestic setting and work-related settings or public places [39]. Furthermore, subjective reports of SHS exposure are subject to recall and reporting biases [23].

A study by Whincup et al. [40] reported substantially higher risks of coronary heart diseases after stratification of the risk based on a biomarker for SHS (cotinine) compared to an indirect assessment via self-report. Cotinine, which is a metabolite of nicotine, is commonly used as a biomarker for measuring SHS exposure [22,37,41]. It can be measured in blood, urine and saliva [42,43] and has a half-life of approximately $15-20 \mathrm{~h} \mathrm{[44]} \mathrm{which} \mathrm{is} \mathrm{much} \mathrm{longer} \mathrm{than} \mathrm{the} \mathrm{half-life} \mathrm{of} \mathrm{nicotine}(2 \mathrm{~h})$ [45-48]. Therefore, cotinine reflects SHS exposure during the previous 1-2 days [33,36,45]. An advantage of cotinine assessment is its ability to detect low quantities of serum cotinine, which allows to identify low levels of SHS exposure among non-smokers [45]. For the interpretation and synthesis of primary studies, these limitations have to be accounted for. Chen et al. [49] concluded that a large cohort study is needed using self-report, cotinine assessment, and the combination of both to reveal reliable information on the association between SHS exposure and adverse health effects. Further investigations are also necessary that take into account exposure to multi-pollutant mixtures using standardized assessments of both exposure and health outcomes [23].

\subsection{Stratification of Results, Bias and Confounding}

Until now, only a few studies have investigated possible mechanisms underlying sex differences in adverse health outcomes of different diseases attributable to SHS exposure. It is assumed that the anti-oestrogenic effect of cigarette smoking - and therefore also the exposure to SHS - may be at least partly related to the increased risk of ischaemic heart diseases in young females smokers [50]. Furthermore, a study by Geisler et al. [51] indicated that in smoking women undergoing oestrogen replacement therapy, plasma levels of oestrogen were $40 \%-70 \%$ lower than in non-smoking women. Additionally, a decrease in both oestradiol and testosterone concentrations in smoking men has been reported [52]. Therefore, hormonal factors seem to considerably influence vulnerability due to SHS exposure. This might also be one explanation for gender differences in the effects of SHS exposure [53].

Epidemiologic studies are subject to different types of bias and confounding. The first type of bias is random error (including errors associated with biological variation, sampling error or measurement error). Precise measurement and adequate study designs may minimize the random error. The second type of bias is systemic error which is difficult to minimize in observational epidemiology since researchers have little control over the study population. Missing to consider a risk factor associated with both the risk factor of interest and disease leads to confounding. It can influence the risk estimate, even changing the apparent direction of an association. Controlling for possible effects of confounding as well as effect modification is a central element in epidemiology. Studies on SHS exposure have 
used various determinants as potential confounders or effect modifiers such as age, gender, smoking status (if not only non-smokers were included), health status and disease history. Nevertheless, a recommendation for further epidemiological studies is to provide adequate controls for the possible effects of confounding due to adjustment, matching, or more restrictive exclusion criteria for study participants $[48,54,55]$. Estimates of risks associated with SHS exposure may differ by factors such as age, gender, socio-economic status, and possibly ethnic susceptibility [56].

Confounding may be related both to the assessment of exposure and the outcome of interest [57]. For example, smoking at some point during life may confound the effect of SHS exposure [58]. The potential for misclassifying the smoking status of former or even current smokers as passive smokers is a longstanding concern in studies using self-reports for assessing SHS exposure [59]. Therefore, the association between SHS exposure and adverse health effects should only be evaluated among never-smokers [60].

\section{Discussion}

The assessment of the impact of potential adverse health effects from environmental risk factors is dependent on several issues such as the hypothesized health outcome, the nature of the exposure, the dose-response-relationship and the variability and susceptibility of the exposed population [8]. To provide information on environmental risk factors, several disciplines such as epidemiology, toxicology and clinical medicine need to contribute to the risk assessment [9].

Since involuntary SHS exposure is a common and serious public health hazard, appropriate regulatory policies need to be adopted and enforced to prevent adverse health effects [61]. The prevention of involuntary population exposures, such as SHS, involves scientific and practical issues quite different from those study designs and activities dealing with the prevention of (sedentary) "lifestyle" factors [62]. As represented by the challenges in creating evidence in environmental health risk assessments, epidemiological studies representing associations between measures of environmental risk factors and health effects are frequently difficult to interpret $[9,63]$.

A major challenge in environmental health studies is the fact that exposures are sometimes very low. Furthermore, most diseases attributable to environmental risk factors are also influenced by other determinants, which may be associated by the personal lifestyle of exposed persons. These confounding factors may lead to inconclusive findings, which are common in the research of SHS exposure and adverse health effects [31,62].

Public health interventions aiming at reduction of exposure of environmental risks are mainly implemented either in household or community settings or by policy means. These interventions are directed at exposed populations which may not be aware of any need for a change or unable to change the risk factor on their own [4], because the risk is (mainly) not associated with the personal characteristics or lifestyles of the exposed person and, therefore, outside the immediate control of the individual $[62,64]$.

\section{Conclusions}

A large body of evidence has shown adverse health effects attributable to SHS exposure. Nevertheless, poor study designs sometimes lead to inconsistent results regarding the SHS exposure associated with adverse health effects. The example of SHS exposure highlights the need for evidence-based public health in the arena of public health decision making to minimize adverse health effects caused by environmental hazards. Several challenges in terms of study design, assessment methods, as well as data analysis and synthesis with respect to the stratification of results, and consideration of bias and confounding exist. Therefore, future research needs to take into account which methods and techniques will be used to generate evidence for population-level decisions, e.g., in terms of a standardized way to measure SHS exposure [29]. Further attention has to be paid to the question how the current evidence will be translated into practice $[1,65]$. 
Acknowledgments: I acknowledge the permission from EMH Swiss Medical Publishers Ltd. to use an adapted version of Figure 1 from the following publication: Künzli, N.; Perez, L. Evidence based public health-The example of air pollution. Swiss Med. Wkly. 2009, 139, 242-250.

Conflicts of Interest: The author declares no conflict of interest.

\section{References}

1. Attena, F. Complexity and indeterminism of evidence-based public health: An analytical framework. Med. Health Care Philos. 2014, 17, 459-465. [CrossRef] [PubMed]

2. Sackett, D.L.; Rosenberg, W.M.; Gray, J.A.; Haynes, R.B.; Richardson, W.S. Evidence based medicine: What it is and what it isn't. BMJ 1996, 312, 71-72. [CrossRef] [PubMed]

3. Victora, C.G.; Habicht, J.P.; Bryce, J. Evidence-based public health: Moving beyond randomized trials. Am. J. Public Health 2004, 94, 400-405. [CrossRef] [PubMed]

4. Rehfuess, E.A.; Bartram, J. Beyond direct impact: Evidence synthesis towards a better understanding of effectiveness of environmental health interventions. Int. J. Hyg. Environ. Health 2014, 217, 155-159. [CrossRef] [PubMed]

5. Brownson, R.C.; Fielding, J.E.; Maylahn, C.M. Evidence-based public health: A fundamental concept for public health practice. Annu. Rev. Public Health 2009, 30, 175-201. [CrossRef] [PubMed]

6. Rychetnik, L.; Frommer, M.; Hawe, P.; Shiell, A. Criteria for evaluating evidence on public health interventions. J. Epidemiol. Commun. Health 2002, 56, 119-127. [CrossRef]

7. Rychetnik, L.; Hawe, P.; Waters, E.; Barratt, A.; Frommer, M. A glossary for evidence based public health. J. Epidemiol. Commun. Health 2004, 58, 538-545. [CrossRef] [PubMed]

8. Rushton, L.; Elliott, P. Evaluating evidence on environmental health risks. Br. Med. Bull. 2003, 68, 113-128. [CrossRef] [PubMed]

9. WHO. Evaluation and use of epidemiological evidence for environmental health risk assessment: Who guideline document. Environ. Health Perspect. 2000, 108, 997-1002.

10. Künzli, N.; Perez, L. Evidence based public health-The example of air pollution. Swiss Med. Wkly. 2009, 139, 242-250. [PubMed]

11. Leone, A.; Giannini, D.; Bellotto, C.; Balbarini, A. Passive smoking and coronary heart disease. Curr. Vasc. Pharmacol. 2004, 2, 175-182. [CrossRef] [PubMed]

12. Hill, S.E.; Blakely, T.; Kawachi, I.; Woodward, A. Mortality among lifelong nonsmokers exposed to secondhand smoke at home: Cohort data and sensitivity analyses. Am. J. Epidemiol. 2007, 165, 530-540. [CrossRef] [PubMed]

13. Lightwood, J.M.; Glantz, S.A. Declines in acute myocardial infarction after smoke-free laws and individual risk attributable to secondhand smoke. Circulation 2009, 120, 1373-1379. [CrossRef] [PubMed]

14. Tunstall-Pedoe, H.; Brown, C.A.; Woodward, M.; Tavendale, R. Passive smoking by self report and serum cotinine and the prevalence of respiratory and coronary heart disease in the scottish heart health study. J. Epidemiol. Commun. Health 1995, 49, 139-143. [CrossRef]

15. Steenland, K.; Thun, M.; Lally, C.; Heath, C. Environmental tobacco smoke and coronary heart disease in the American Cancer Society CPS-II cohort. Circulation 1996, 94, 622-628. [CrossRef] [PubMed]

16. Jousilahti, P.; Patja, K.; Salomaa, V. Environmental tobacco smoke and the risk of cardiovascular disease. Scand. J. Work Environ. Health 2002, 28, 41-51. [PubMed]

17. Pitsavos, C.; Panagiotakos, D.B.; Chrysohoou, C.; Tzioumis, K.; Papaioannou, I.; Stefanadis, C.; Toutouzas, P. Association between passive cigarette smoking and the risk of developing acute coronary syndromes: The cardio2000 study. Heart Vessels 2002, 16, 127-130. [PubMed]

18. Steenland, K. Passive smoking and the risk of heart disease. JAMA 1992, 267, 94-99. [CrossRef] [PubMed]

19. Glantz, S.A.; Parmley, W.W. Passive smoking and heart disease. Epidemiology, physiology, and biochemistry. Circulation 1991, 83, 1-12. [CrossRef] [PubMed]

20. Enstrom, J.E.; Kabat, G.C. Environmental tobacco smoke and coronary heart disease mortality in the united states-A meta-analysis and critique. Inhal. Toxicol. 2006, 18, 199-210. [CrossRef] [PubMed]

21. Bonita, R.; Duncan, J.; Truelsen, T.; Jackson, R.T.; Beaglehole, R. Passive smoking as well as active smoking increases the risk of acute stroke. Tob. Control 1999, 8, 156-160. [CrossRef] [PubMed] 
22. Avila-Tang, E.; Elf, J.L.; Cummings, K.M.; Fong, G.T.; Hovell, M.F.; Klein, J.D.; McMillen, R.; Winickoff, J.P.; Samet, J.M. Assessing secondhand smoke exposure with reported measures. Tob. Control 2013, 22, 156-163. [CrossRef] [PubMed]

23. Bentayeb, M.; Simoni, M.; Norback, D.; Baldacci, S.; Maio, S.; Viegi, G.; Annesi-Maesano, I. Indoor air pollution and respiratory health in the elderly. J. Environ. Sci. Health A 2013, 48, 1783-1789. [CrossRef] [PubMed]

24. Barnoya, J.; Glantz, S.A. Cardiovascular effects of secondhand smoke: Nearly as large as smoking. Circulation 2005, 111, 2684-2698. [CrossRef] [PubMed]

25. He, J.; Vupputuri, S.; Allen, K.; Prerost, M.R.; Hughes, J.; Whelton, P.K. Passive smoking and the risk of coronary heart disease-A meta-analysis of epidemiologic studies. N. Engl. J. Med. 1999, 340, 920-926. [CrossRef] [PubMed]

26. Rostron, B. Mortality risks associated with environmental tobacco smoke exposure in the United States. Nicot. Tob. Res. 2013, 15, 1722-1728. [CrossRef] [PubMed]

27. Ahijevych, K.; Wewers, M.E. Passive smoking and vascular disease. J. Cardiovasc. Nurs. 2003, 18, 69-74. [CrossRef] [PubMed]

28. Pron, G.E.; Burch, J.D.; Howe, G.R.; Miller, A.B. The reliability of passive smoking histories reported in a case-control study of lung cancer. Am. J. Epidemiol. 1988, 127, 267-273. [PubMed]

29. Thun, M.; Henley, J.; Apicella, L. Epidemiologic studies of fatal and nonfatal cardiovascular disease and ETS exposure from spousal smoking. Environ. Health Perspect. 1999, 107 (Suppl. S6), 841-846. [CrossRef] [PubMed]

30. Kaur, S.; Cohen, A.; Dolor, R.; Coffman, C.J.; Bastian, L.A. The impact of environmental tobacco smoke on women's risk of dying from heart disease: A meta-analysis. J. Women's Health 2004, 13, 888-897. [CrossRef] [PubMed]

31. Oono, I.P.; Mackay, D.F.; Pell, J.P. Meta-analysis of the association between secondhand smoke exposure and stroke. J. Public Health 2011, 33, 496-502. [CrossRef] [PubMed]

32. Brownson, R.C.; Alavanja, M.C.; Hock, E.T. Reliability of passive smoke exposure histories in a case-control study of lung cancer. Int. J. Epidemiol. 1993, 22, 804-808. [CrossRef] [PubMed]

33. Eisner, M.D.; Balmes, J.; Katz, P.P.; Trupin, L.; Yelin, E.H.; Blanc, P.D. Lifetime environmental tobacco smoke exposure and the risk of chronic obstructive pulmonary disease. Environ. Health 2005, 4. [CrossRef] [PubMed]

34. Emmons, K.M.; Abrams, D.B.; Marshall, R.; Marcus, B.H.; Kane, M.; Novotny, T.E.; Etzel, R.A. An evaluation of the relationship between self-report and biochemical measures of environmental tobacco smoke exposure. Prev. Med. 1994, 23, 35-39. [CrossRef] [PubMed]

35. Coultas, D.B.; Peake, G.T.; Samet, J.M. Questionnaire assessment of lifetime and recent exposure to environmental tobacco smoke. Am. J. Epidemiol. 1989, 130, 338-347. [PubMed]

36. Hammond, S.K.; Leaderer, B.P. A diffusion monitor to measure exposure to passive smoking. Environ. Sci. Technol. 1987, 21, 494-497. [CrossRef] [PubMed]

37. Jefferis, B.J.; Lawlor, D.A.; Ebrahim, S.; Wannamethee, S.G.; Feyerabend, C.; Doig, M.; McMeekin, L.; Cook, D.G.; Whincup, P.H. Cotinine-assessed second-hand smoke exposure and risk of cardiovascular disease in older adults. Heart 2010, 96, 854-859. [CrossRef] [PubMed]

38. Lightwood, J.M.; Coxson, P.G.; Bibbins-Domingo, K.; Williams, L.W.; Goldman, L. Coronary heart disease attributable to passive smoking: CHD policy model. Am. J. Prev. Med. 2009, 36, 13-20. [CrossRef] [PubMed]

39. Iribarren, C.; Darbinian, J.; Klatsky, A.L.; Friedman, G.D. Cohort study of exposure to environmental tobacco smoke and risk of first ischemic stroke and transient ischemic attack. Neuroepidemiology 2004, 23, 38-44. [CrossRef] [PubMed]

40. Whincup, P.H.; Gilg, J.A.; Emberson, J.R.; Jarvis, M.J.; Feyerabend, C.; Bryant, A.; Walker, M.; Cook, D.G. Passive smoking and risk of coronary heart disease and stroke: Prospective study with cotinine measurement. BMJ 2004, 329, 200-205. [CrossRef] [PubMed]

41. Misailidi, M.; Tzatzarakis, M.N.; Kavvalakis, M.P.; Koutedakis, Y.; Tsatsakis, A.M.; Flouris, A.D. Instruments to assess secondhand smoke exposure in large cohorts of never smokers: The smoke scales. PLoS ONE 2014, 9. [CrossRef] [PubMed]

42. Jarvis, M.J.; Tunstall-Pedoe, H.; Feyerabend, C.; Vesey, C.; Saloojee, Y. Comparison of tests used to distinguish smokers from nonsmokers. Am. J. Public Health 1987, 77, 1435-1438. [CrossRef] [PubMed] 
43. Bernert, J.T., Jr.; McGuffey, J.E.; Morrison, M.A.; Pirkle, J.L. Comparison of serum and salivary cotinine measurements by a sensitive high-performance liquid chromatography-tandem mass spectrometry method as an indicator of exposure to tobacco smoke among smokers and nonsmokers. J. Anal. Toxicol. 2000, 24, 333-339. [CrossRef] [PubMed]

44. Benowitz, N.L.; Kuyt, F.; Jacob, P., III; Jones, R.T.; Osman, A.L. Cotinine disposition and effects. Clin. Pharmacol. Ther. 1983, 34, 604-611. [CrossRef] [PubMed]

45. Nondahl, D.M.; Cruickshanks, K.J.; Schubert, C.R. A questionnaire for assessing environmental tobacco smoke exposure. Environ. Res. 2005, 97, 76-82. [CrossRef] [PubMed]

46. Hawamdeh, A.; Kasasbeh, F.A.; Ahmad, M.A. Effects of passive smoking on children's health: A review. East. Mediterr. Health J. 2003, 9, 441-447. [PubMed]

47. Jarvis, M.; Tunstall-Pedoe, H.; Feyerabend, C.; Vesey, C.; Salloojee, Y. Biochemical markers of smoke absorption and self reported exposure to passive smoking. J. Epidemiol. Commun. Health 1984, 38, 335-339. [CrossRef]

48. Jarvis, M.J.; Russell, M.A.; Benowitz, N.L.; Feyerabend, C. Elimination of cotinine from body fluids: Implications for noninvasive measurement of tobacco smoke exposure. Am. J. Public Health 1988, 78, 696-698. [CrossRef] [PubMed]

49. Chen, R.; Tavendale, R.; Tunstall-Pedoe, H. Environmental tobacco smoke and prevalent coronary heart disease among never smokers in the scottish monica surveys. Occup. Environ. Med. 2004, 61, 790-792. [CrossRef] [PubMed]

50. Baron, J.A.; la Vecchia, C.; Levi, F. The antiestrogenic effect of cigarette smoking in women. Am. J. Obstet. Gynecol. 1990, 162, 502-514. [CrossRef]

51. Geisler, J.; Omsjo, I.H.; Helle, S.I.; Ekse, D.; Silsand, T.; Lonning, P.E. Plasma oestrogen fractions in postmenopausal women receiving hormone replacement therapy: Influence of route of administration and cigarette smoking. J. Endocrinol. 1999, 162, 265-270. [CrossRef] [PubMed]

52. Hsieh, C.C.; Signorello, L.B.; Lipworth, L.; Lagiou, P.; Mantzoros, C.S.; Trichopoulos, D. Predictors of sex hormone levels among the elderly: A study in greece. J. Clin. Epidemiol. 1998, 51, 837-841. [CrossRef]

53. Bolego, C.; Poli, A.; Paoletti, R. Smoking and gender. Cardiovasc. Res. 2002, 53, 568-576. [CrossRef]

54. McElduff, P.; Dobson, A.J.; Jackson, R.; Beaglehole, R.; Heller, R.F.; Lay-Yee, R. Coronary events and exposure to environmental tobacco smoke: A case-control study from australia and new zealand. Tob. Control 1998, 7 , 41-46. [CrossRef] [PubMed]

55. Dunbar, A.; Gotsis, W.; Frishman, W. Second-hand tobacco smoke and cardiovascular disease risk: An epidemiological review. Cardiol. Rev. 2013, 21, 94-100. [CrossRef] [PubMed]

56. Ding, D.; Fung, W.H.; Zhang, Q.; Yip, G.W.K.; Chan, C.K.; Yu, C.M. Effect of household passive smoking exposure on the risk of ischaemic heart disease in never-smoke female patients in hong kong. Tob. Control 2009, 18, 354-357. [CrossRef] [PubMed]

57. Iribarren, C.; Friedman, G.D.; Klatsky, A.L.; Eisner, M.D. Exposure to environmental tobacco smoke: Association with personal characteristics and self reported health conditions. J. Epidemiol. Commun. Health 2001, 55, 721-728. [CrossRef]

58. Johannessen, A.; Bakke, P.S.; Hardie, J.A.; Eagan, T.M. Association of exposure to environmental tobacco smoke in childhood with chronic obstructive pulmonary disease and respiratory symptoms in adults. Respirology 2012, 17, 499-505. [CrossRef] [PubMed]

59. Coultas, D.B. Passive smoking and risk of adult asthma and copd: An update. Thorax 1998, 53, 381-387. [CrossRef] [PubMed]

60. Enstrom, J.E.; Kabat, G.C. Environmental tobacco smoke and tobacco related mortality in a prospective study of californians, 1960-98. BMJ 2003, 326, 1057. [CrossRef] [PubMed]

61. Reardon, J.Z. Environmental tobacco smoke: Respiratory and other health effects. Clin. Chest Med. 2007, 28, 559-573. [CrossRef] [PubMed]

62. Pekkanen, J.; Pearce, N. Environmental epidemiology: Challenges and opportunities. Environ. Health Perspect. 2001, 109, 1-5. [CrossRef] [PubMed]

63. Neutra, R.R.; Trichopoulos, D. The place of epidemiology in environmental decisions: Needed support for the development of risk assessment policy. Environ. Health Perspect. 1993, 101 (Suppl. S4), 67-69. [CrossRef] [PubMed] 
64. Rothman, K.J. Methodological frontiers in environmental epidemiology. Environ. Health Perspect. 1993, 101, 19-21. [CrossRef] [PubMed]

65. Rychetnik, L.; Bauman, A.; Laws, R.; King, L.; Risse, D.; Nutbeam, D. Translating research for evidence-based public health: Key concepts and future directions. J. Epidemiol. Commun. Health 2012, 66, 1187-1192. [CrossRef] [PubMed]

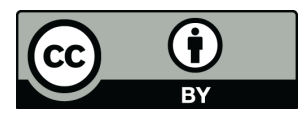

(C) 2016 by the author; licensee MDPI, Basel, Switzerland. This article is an open access article distributed under the terms and conditions of the Creative Commons by Attribution (CC-BY) license (http://creativecommons.org/licenses/by/4.0/). 